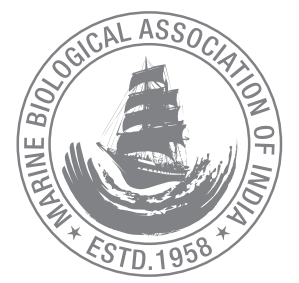

\title{
Rare observation of scar-bearing cuttlebone in a wild-caught Sepia pharaonis (Cephalopoda: Sepiidae) from southeastern Arabian Sea
}

\author{
V. Venkatesan*, K. K. Sajikumar, P. S. Alloycious, K. M. Jestin Joy and K. S. Mohamed \\ ICAR-Central Marine Fisheries Research Institute, Kochi-682 018, Kerala, India. \\ *Correspondence e-mail: venkatcmfri@yahoo.co.in
}

Received: 15 Nov 2019 Accepted: 18 July 2020 Published: 25 July 2020

\begin{abstract}
A rare observation of the severely fractured cum healing cuttlebone of wild-caught Sepia pharaonis is reported and discussed here. The observation showed that cuttlebone of one specimen was severely affected by scars. Scars were interpreted as oval-shaped teeth marks on the dorsal side having a diameter of $23 \mathrm{~mm}$. Several other teeth marks (3-4 numbers) were also observed at the anterodorsal region. Fracture was completely healed at the dorsal side while fracture (19 $\mathrm{mm}$ length) was notable in posteroventral region. Inverted 'V'shaped blackline was also observed on the posteroventral region. However, scar-bearing cuttlebones was more or less symmetrical with respect to the sagittal plane.
\end{abstract}

Keywords: Scar-bearing cuttlebone, Sepia pharaonis, southeastern Arabian Sea

\section{Introduction}

Cuttlebone or cuttlefish bone is a hard, brittle internal shell/ structure found in all members of cuttlefish family Sepiidae, belonging to the phylum Mollusca, class Cephalopoda. Cuttlebone comprises superimposed chambers that have a complex internal arrangement of calcified pillars and membranes (Checa et al., 2015). This gas filled chambers/shell is used for buoyancy control (Rexfort and Mutterlose, 2006). Cephalopods do not retain many hard structures after death but the few structures that remain even after death include nautilus shells, beaks, and cuttlebones (Barord, 2011). Hard structures such as nautilus shells and cuttlebones, may deliver evidence of life history behaviours and strategies of both living and nonliving cephalopods and regulate the buoyancy of Nautilus and cuttlefish respectively (Barord, 2011).

Internal structures of all cephalopods including cuttlefish may possibly deteriorate rapidly after death, so that the fundamental aspects of anatomy cannot be traced back. Hence, cuttlebone may be the only record of past trauma (Feral, 1978). Cases of abnormal or scarred cuttlebones in the genus Sepia (Sepiidae) have been reported by many authors (Battiato, 1983; Boletzky and Overath, 1991; Sherrill et al., 2000; Bello and Paparella, 2003). The occurrence of scars on cuttlebones of wild caught 
cuttlefish Sepia orbignyana from the south-western Adriatic Sea, off Mola di Bari was reported by Bello and Paparella (2003).

Present study reports the occurrence of severely fractured cum healing cuttlebone of wild-collected Sepia pharaonis, Ehrenberg, 1831 from southeastern Arabian Sea. This cephalopod is one of the commercially important species of demersal resource, known to occur in fairly shallow depths over a wide geographic range (Reid et al., 2005). Sepia pharaonis has been assessed as Data Deficient by IUCN and is prevalent in global marine environments (Barratt, and Allcock, 2012). It is fished as target and bycatch, and in artisanal and commercial fisheries (Reid et al., 2005). It forms about $90 \%$ of all cuttlefish caught by Australian and Chinese trawlers (Reid et al., 2005). Global capture fisheries production of cephalopods is 4.5 million tonnes in 2016 (FAO, 2018). Indian cephalopods catch contributed $5 \%$ (i.e. about 0.2 million tonnes) of the global cephalopod catch in 2016. Average annual $S$. pharaonis catch from India for the period 2017-18 was 87,271 tonnes (CMFRI, 2018).

\section{Material and methods}

Samples of cuttlefishes were collected from the Cochin Fisheris Harbour (CFH) on 26 June, 2018. A single scar-bearing cuttlebone of $S$. pharaonis was diagnosed while observing the biology sample in the laboratory. Detailed observations were made and morphometric measurements were taken. On enquiry, fishers revealed that this cuttlefish was caught from a commercial trawl operating off Kollam (depth 50-70 m) in southeastern Arabian Sea.

\section{Results and discussion}

While analysing the biology of $S$. pharaonis samples, a single scar bearing cuttlebone $(55 \mathrm{~mm}$ ) of $S$. pharaonis ( $58 \mathrm{~mm}$ Dorsal Mantle Length (DML)) was observed. Externally, no evident anomalies were detected on the body surface of $S$. pharaonis during its examination. The specimen was caught from the commercial trawl operated at about 50-70m depth. Juvenile (upto $100 \mathrm{~mm} \mathrm{DML}$ ) cuttlefishes of this species occur in inshore waters and are obtained in trawl nets off Cochin area all the year around except in June and December (Silas et al., 1985). The size of the present specimen was below the Minimum Legal Size fixed as a fisheries management tool to protect juvenile cuttlefish (100 mm DML) along the Kerala Coast (Mohamed et al., 2014).

Details of the observations and morphometric measurements of the cuttlebone scars are shown in Table 1. There were several morpholoical differences recorded in the cuttlebone most notably an oval-shaped teeth scar at the dorsal side (Fig. 1). Oval-shaped scars were almost completely healed.
It is very obvious from the figure that scars were more on the dorsal side compared to the ventral. Another 3-4 teeth scars were also noted on the dorsal side. Other than oval shaped scar, several marks were observed at anterodorsal sides (Fig. 1 D-E). Fracture on the dorsal side was completely healed while the fracture was still visible on the ventral side. Scarring in posteroventral zone of cuttlebone was evident by black lines. Inverted ' $V$ ' shaped black line was also observed on the ventral side. Owing to healing especially on the dorsal side, scar-bearing cuttlebone was more or less symmetrical with respect to the sagittal plane. Generally, in case of such trauma, scar bearing cuttlebones become asymmetrical with regard to the sagittal plane (Bello and Paparella, 2003).

Oval shaped scars on the dorsal side of cuttlebone were observed in the present study. This species ascends the water column at night to feed on small fish and crustaceans (Reid et al., 2005). It seemed that this juvenile cuttlefish narrowly escaped predation by a large fish which resulted in oval shaped scars. As biting of teeth occurred in dorsal side, scars are relatively larger on dorsal side. Owing to force of teethbite, posterior portion of cuttlebone was fractured. Generally posterior portion of cuttlebone is weaker than anterior (Cadee, 1997). Cuttlebones of certain cuttlefish are dorsally hard but ventrally soft. All these factors resulted in fracture of bone. As the predator attacked on the dorsal side of cuttlefish, it might have escaped from predator because cuttlebones are dorsally hard. Oval scar ( $23 \mathrm{~mm} \mathrm{dia)} \mathrm{on} \mathrm{the} \mathrm{cuttlebone} \mathrm{indicates} \mathrm{mouth-size} \mathrm{of} \mathrm{the}$ predator which is too small to engulf the prey. Fig.1 clearly shows that dorsal side is completely healed while the fracture is still visible at the ventral side. Coleoid cephalopods, which include cuttlefish serve as an important prey resource to a wide range of fishes, marine mammals, birds, and other invertebrates including conspecifics (Blanc and Daguzan, 2000; Staudinger and Juanes, 2010). Cephalopods that live in shallow-water habitats are thought to largely depend on primary defense (i.e., crypsis) for protection (Staudinger et al., 2013). Being a juvenile cuttlefish, the present specimen would not have been efficient to avoid the predator attack completely. Bello and Paparella (2003) observed that the scars on the two of cuttlebones of wild caught cuttlefish $S$. orbignyana from the south-western Adriatic Sea, off Mola di Bari was due to fish

\begin{tabular}{ll} 
Table 1. Morphometric measurements of the cuttlebone of S. pharaonis & \\
\hline Measurements & (mm) \\
\hline Dorsal mantle length & 58 \\
\hline Total weight (g) & 34 \\
\hline Cuttlebone length & 55 \\
\hline Oval shaped scar (dia) & 23 \\
\hline Length of fracture (Fig. 1A) & 19 \\
\hline Sex & male
\end{tabular}




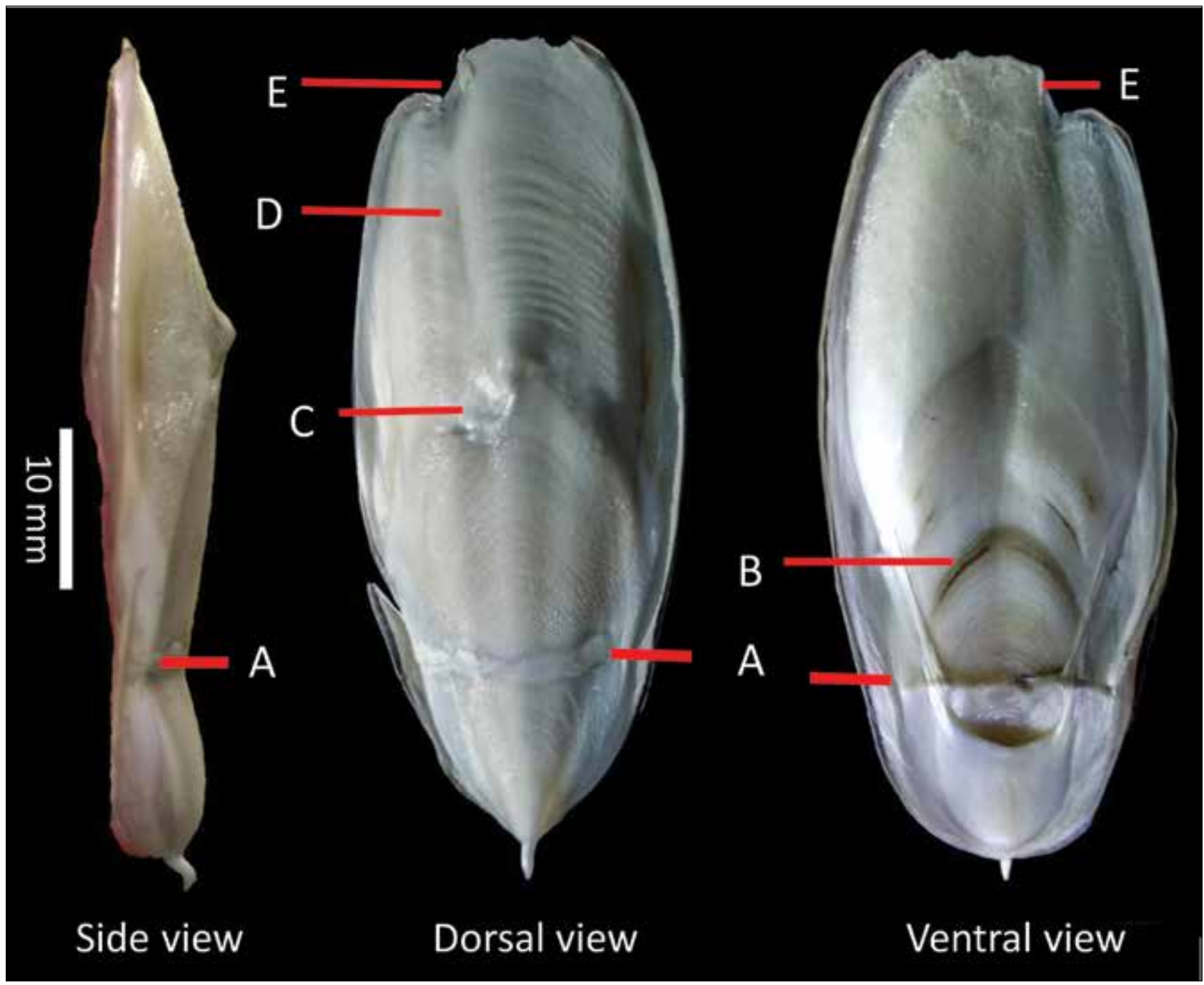

Fig. 1 Side, dorsal and ventral views of scarred cuttlebone (immature male, $58 \mathrm{~mm} \mathrm{DML).} A=$ horizontal breakage cum healing of cuttlebone, $B=$ blackline, $C=$ deep teeth scar $(1-2 \mathrm{~mm}$ deep) on the dorsal surface, $\mathrm{D} \& \mathrm{E}=$ presumptive fish teeth mark. Scale $=10 \mathrm{~mm}$.

teeth. Staudinger et al. (2013) studied antipredatory behaviour of cuttlefish S. officinalis to three teleost predators - bluefish (Pomatomus saltatrix), summer flounder (Paralichthys dentatus), and black seabass (Centropristis striata). Predator of cuttlefish S. officinalis are fish [e.g. sea bass Dicentrarchus sp.] and sea mammals [e.g. bottlenose dolphin (Tursiops sp.)] (Hanlon and Messenger, 1988; Kier and Leeuwen, 1997).

Internal structures such as cuttlebone are the unpressurized systems that do not considerably change in volume and able to withstand the hydrostatic pressure at increased depth (Denton and Gilpin-Brown, 1961). Nevertheless, this buoyancy system is absolutely unchanged during vertical movements (Denton, 1974; Ward, 1987). Hence, it appears doubtful that cuttlefish could possibly become victims of accidental downward movement from their usual depth (Bello and Paparella, 2003).
The fractured cuttlebone was almost healed from the traumatic event of escape from predator. It is highly likely that the healing observed on the lateral edge of the cuttlebone is a result of the repair capacity of the species. Cephalopod immune systems are well adapted to natural environments, may not be suitable for stress related to captivity, leading to disease (Sherrill et al., 2000). Despite Cephalopods like all other invertebrates lack an adaptive immune system (Marchalonis, 1977; Warr, 1981), it posses an effective immune system that allow them to interact with microbes, detect and eliminate pathogens and healing tissue damage and wound (Iwanaga and Lee, 2005). Like other invertebrates, Cephalopods posses blood cellular components (hemocytes) that have a variety of defence functions including phagocytosis, killing and tissue repair (Jenkin, 1976). Similarly, Cephalopods have the ability to repair and regenerate their body parts after traumatic events (Bello and Paparella, 2003). 
Repairs on calcified external or internal shell are common in fossil and extant cephalopods (Keupp, 2000). Incidences of post-traumatic repairs of hard structures in cephalopods are marked as scars (Bello and Paparella, 2003).

Cuttlebone fractures were noticed in 10 captive cuttlefish at the Smithsonian National Zoological Park (NZP) and these were characterized as brittle and malformed (Sherrill et al., 2000). Possible reasons for the abnormal cuttlebones development in captive cephalopods include nutritional deficiencies, water temperatures outside of normal ranges, or stress induced by excessive nitrogenous waste compounds which can adversely affect cuttlebone mineral deposition and growth rate (Forsythe et al., 1994; Lee, 1994; LeGoff et al., 1998).

Black line along the ventral portion as observed in the present study may be evidence of trauma. Similar observations were noted in several cuttlebones of $S$. pharaonis and $S$. officinalis by Barord (2011). He also observed the scarring in wild nautilus and several cuttlebones of $S$. pharaonis and S. officinalis.

Whatever may be root cause of scarring in the cuttlebone of the current wild-caught $S$. pharaonis, this animal possess good capabilities of overcoming certain trauma. Similar observations were indicated by Ward and Boletzky (1984) and Bello and Paparella (2003) in S. orbignyana.

\section{References}

Barord, G. J. 2011. Post-mortem analysis of cuttlebones provides critical insight into the natural history of captive cuttlefish, sepia. Drum and Croaker, 42:20-29.

Barratt, I. and L. Allcock. 2012. Sepia pharaonis. The IUCN Red List of Threatened Species 012:e.T162504A904257.http://dx.doi.org/10.2305/ IUCN.UK.20121. RLTS. T162504A904257.en.

Battiato, A. 1983. Su un sepiostario aberrante di Sepia officinalis L. (Cephalopoda, Sepiidae). Thalassia Salentina, 12-13: 152-153.

Bello, G. and P. Paparella. 2003. Scar-bearing cuttlebones in wild-collected Sepia orbignyana (Cephalopoda: Sepiidae) and the effects of scar occurrence on morphometric relationships. Coleoid cephalopods through time, 03:13-18.

Blanc, A. and J. Daguzan. 2000. Size selectivity in the diet of the young cuttlefish Sepia officinalis (Mollusca: Sepiidae). J. Mar. Biol. Assoc. UK, 80: 1137-1138.

Boletzky, Sv. and H. Overath. 1991. Shell fracture and repair in the cuttlefish Sepia officinalis. In: Boucaud-Camou E (ed.) La seiche-The cuttlefish. Acta of the first International Symposium on the Cuttlefish Sepia. Centre de publication de I'Université de Caen, p. 69-78.

Cadee, G. C. 1997. Invasie van Sepia oficinalis schilden op Texel in 1996.-Het Zeepaard 57: 10-19.

Checa, A. G., J. H. E. Cartwright, I. Sanchez-Almazo, J. P. Andrade and F. RuizRaya. 2015. The cuttlefish Sepia officinalis (Sepiidae, Cephalopoda) constructs cuttlebone from a liquid-crystal precursor. Scientific Reports, 5:11513.

CMFRI, 2018. ICAR-CMFRI Annual Report 2017-18, Central Marine Fisheries Research Institute, Kochi.
Denton, E. J. 1974. On the buoyancy and lives of modern and fossil cephalopods. Proc. R. Soc. Lond. B., 185:273-299.

Denton, E. J. and J. B. Gilpin-Brown. 1961. The buoyancy of the cuttlefish Sepia officinalis. J. Mar. Biol. Assoc. UK, 41:319-342.

FAO. 2018. The State of World Fisheries and Aquaculture 2018-Meeting the sustainable development goals. Rome. Licence: CC BY-NC-SA 3.0 IGO.

Feral, J. P. 1978. La regeneration des bras de la seiche Sepia officinalis L. (Cephalopoda, Sepioidea). I. Etude morphologique. Cah Biol Mar., 19:355-361.

Forsythe, J. W., R. H. DeRusha and R. T. Hanlon. 1994. Growth, reproduction and life span of Sepia officinalis (Cephalopoda: Mollusca) cultured through seven consecutive generations. J. Zool. Lond., 233: 175-192.

Hanlon, R. T. and J. B. Messenger. 1988. Adaptive coloration in young cuttlefish (Sepia officinalis L.): the morphology and development of body patterns and their relation to behaviour. Philos. Trans. R. Soc. B., 320: 437-487.

Iwanaga, S. and B. L. Lee. 2005. Recent advances in the innate immunity of invertebrate animals. J. Biochem. Mol. Biol., 38(2): 128-150.

Jenkin, C. R. 1976. Factors involved in the recognition of foreign material by phagocytic cells from invertebrates, In: Marchalonis, J. J. (Ed.), Comparative immunology, Wiley, New York, p. 80-97.

Keupp, H. 2000. Anomale Muskelleisten bei Ammoniten. Berliner geowiss Abh E 34: 279- 289.

Kier, W. M. and J. L. Leeuwen. 1997. A kinematic analysis of tentacle extension in the squid Loligo pealei. J. Exp. Biol., 200: 41-53.

Lee, P. G. 1994. Nutrition of cephalopods: fueling the system. Mar. Fresh w. Behav. Physiol., 25: 35-51.

LeGoff, R., E. Gauvrit, G. Pinczon du Sel and J. Daguzan. 1998. Age group determination by analysis of the cuttlebone of the cuttlefish Sepia officinalis L. in reproduction in the Bay of Biscay. J. Molluscan. Stud., 64:183-193.

Marchalonis, J. J. 1977. Immunity in evolution, Harvard University Press, Cambridge, Massachessetts.

Mohamed, S. K., P. U. Zacharia, G. Maheswarudu, T. V. Sathianandan, E. M. Abdussamad, U. Ganga, S. Lakshmi Pillai, K. S. Sobhana, Rekha J. Nair, Josileen Jose, Rekha D. Chakraborty, S. Kizhakudan, and T. M. Najmudeen. 2014. Minimum Legal Size (MLS) of capture to avoid growth overfishing of commercially exploited fish and shellfish species of Kerala. Mar. Fish. Infor. Serv., T\& E Ser., No. 220: 3-7.

Reid, A., P. Jereb, and C. F. E. Roper. 2005. Family Sepiidae. In: P. Jereb and C.F.E Roper (eds), Cephalopods of the World. An Annotated and Illustrated Catalogue of Cephalopod Species Known to Date. Volume 1. Chambered Nautiluses and Sepioids (Nautilidae, Sepiidae, Sepiolidae, Sepiadariidae, Idiosepiidae and Spirulidae), p. 54- 152. FAO, Rome.

Rexfort, A. and J. Mutterlose. 2006. Stable isotope records from Sepia officinalis-a key to understanding the ecology of belemnites? Earth Planet. Sci. Lett., 247(3-4): 212- 212 .

Sherrill J., L. H. Spelman, C. L. Reidel and R. J. Montali. 2000. Common cuttlefish (Sepia officinalis) mortality at the National Zoological Park: implications for clinical management. J. Zoo Wildl. Med., 31: 523-531.

Silas, E. G., R. Sarvesan, K. P. Nair, Y. A. Sastry, P. V. Srinivasan, M. M. Meiyappan, Kuber Vidyasagar, K. S. Rao and B. N. Rao. 1985. Some aspects of the biology of Cuttlefishes. In: Silas, E. G. (Ed.) Cephalopod bionomics, fisheries and resources of the Exclusive Economic Zone of India. Bull. Cent. Mar. Fis. Res. Inst., 37: $49-70$.

Staudinger, M. D. and F. Juanes. 2010. A size-based approach to quantifying predation on longfin inshore squid (Loligo pealeii) in the northwest Atlantic. Mar. Ecol. Prog. Ser. 399: 225-241.

Staudinger, M. D., K. C. Buresch, L. M. Mäthger, C. Fry, S. McAnulty, K. M. Ulmer and R. T. Hanlon. 2013. Defensive responses of cuttlefish to different teleost predators. Biol. Bull., 225(3): 161-174.

Ward, P. 1987. The Natural History of the Nautilus. Allen and Unwin, Boston.

Ward, P. D. and Sv. Boletzky. 1984. Shell implosion depth and implosion morphologies in three species of Sepia (Cephalopoda) from the Mediterranean Sea. J. Mar. Biol. Assoc. UK, 64: 955-966.

Warr, G. W. 1981. Immunity in invertebrates, J. Invert. Pathol., 38: 311-314. 